\title{
Striking the balance between PTEN and PDK1: it all depends on the cell context
}

\author{
Akio Iwanami, ${ }^{1}$ Timothy F. Cloughesy, ${ }^{1,2}$ and Paul S. Mischel ${ }^{1,2,3}$ \\ ${ }^{1}$ Department of Pathology and Laboratory Medicine, the Henry Singleton Brain Tumor Program at the David Geffen University \\ of California at Los Angeles School of Medicine, Los Angeles, California 90095, USA; ${ }^{2}$ Department of Neurology, the Henry \\ Singleton Brain Tumor Program at the David Geffen University of California at Los Angeles School of Medicine, Los Angeles, \\ Calforinia 90095, USA; ${ }^{3}$ Department of Molecular and Medical Pharmacology, the Henry Singleton Brain Tumor Program at the \\ David Geffen University of California at Los Angeles School of Medicine, Los Angeles, Californai 90095, USA
}

The phosphatidyl-inosital-3 kinase (PI3K) signaling pathway is critical for normal brain development and function and is commonly hyperactivated in brain cancer. The PTEN (phosphatase and tensin homolog deleted on chromosome 10) tumor suppressor protein and phosphatedepended kinase 1 (PDK-1) are critical regulators of this pathway. In the July 15, 2009, issue of Genes \& Development, Chalhoub and colleagues (pp. 1619-1624) demonstrate PDK1-dependent and PDK1-independent effects of conditional PTEN deletion in the brain, and they identify cell type-specific differences in feedback regulation of the PI3K pathway. These studies provide important insights as to how neurons and glia may differentially regulate PI3K signaling, yielding intriguing clues about targeting PTEN-deficient brain cancers.

Phosphatidyl-inosital-3 kinases (PI3Ks) are a family of highly conserved intracellular lipid kinases that regulate cellular proliferation, differentiation, metabolism, and survival (Engelman et al. 2006). Akt/PKB (henceforth referred to as Akt) and mammalian target of rapamycin (mTOR) are enzymatic effectors of PI3K signaling (Engelman et al. 2006). PI3K signaling is critical for normal development and function, and defects in its regulation result in a variety of neurological and developmental diseases and cancer (Vivanco and Sawyers 2002; Engelman et al. 2006; Endersby and Baker 2008).

Class IA PI3Ks are activated by growth factor receptor tyrosine kinases (RTKs) either directly or through interaction with the insulin receptor substrate family of adaptor molecules (Engelman et al. 2006). The activity of PI3K results in the production of phosphatidylinositol-3,4,5-trisphospate (PIP3), a critical regulator of the serine/threonine kinase Akt to link growth factor signaling with cellular growth, proliferation, metabolism, and survival (Engelman et al. 2006; Chalhoub and Baker 2009). Akt is recruited to the membrane through interaction of its pleckstrin homol-

[Keywords: PI3K; Pdk1; Pten; brain; feedback; migration] ${ }^{1}$ Corresponding author.

E-MAIL pmischel@mednet.ucla.edu; FAX (310) 794-4161.

Article is online at http://www.genesdev.org/cgi/doi/10.1101/gad.1832909. ogy $(\mathrm{PH})$ domain with $\mathrm{PIP} 3$, thus exposing its activation loop and enabling phosphorylation at Thr308 by the constitutively active phosphate-dependent kinase (PDK1) (Alessi et al. 1997; Calleja et al. 2007, 2009). For maximal activation, Akt is also phosphorylated on Ser473 of its Cterminal hydrophobic motif by mTOR, as described below.

$\mathrm{mTOR}$ is both an effector and an activator of Akt signaling, thus linking growth factor signaling through PI3K with protein translation, cell growth, proliferation, metabolism, and survival. mTOR exists in two multiprotein complexes, each characterized by different binding partners with distinct activities. $\mathrm{mTOR}$ resides in a complex with PRAS40, raptor, and $\mathrm{mLST}$ /G $\beta \mathrm{L}$ as part of mTOC complex 1 (mTORC1). mTORC2 is composed of $\mathrm{mTOR}$ in complex with rictor, $\mathrm{mSIN} 1$, protor, and mLST8 (Guertin and Sabatini 2009). The recently identified mTOR inhibitor DEPTOR associates with both complexes, as will be described below (Peterson et al. 2009). Akt activates mTORC1 by inhibitory phosphorylation of TSC2, which, along with TSC1, negatively regulates mTORC1 by inhibiting the Rheb GTPase, a positive regulator of $\mathrm{mTORC1}$. Rather surprisingly, a PKC $\alpha$-dependent, Akt-independent route linking PI3K with mTORC1 has been described recently, suggesting that there may be multiple routes between PI3K and mTORC1 (Fan et al. 2009). mTORC1 has two welldefined substrates-p70S6K (referred to hereafter as S6K1) and 4E-BP1-both of which critically regulate protein synthesis (Guertin and Sabatini 2009). Unlike mTORC1, which is regulated by Akt, mTORC2 is an Akt activator. PI3K signaling activates mTORC2, which in turn activates a number of kinases in addition to Akt, including serum glucocorticoid-induced protein kinase (SGK1) and PKC $\alpha$, all of which may also play important roles in regulating cellular proliferation and growth.

PTEN (phosphatase and tensin homolog deleted on chromosome 10) is the critical negative regulator of PI3K signaling: role in neurological disease and cancer

Unrestrained signaling through the PI3K pathway has disastrous consequences for the cell and the organism, 
including the development of cancer. The PTEN tumor suppressor protein is the major negative regulator of the PI3K pathway. PTEN antagonizes PI3K signaling by dephosphorylating PIP3. Unlike other pathway components, there are no other PTEN-like proteins that can compensate for its loss of function, so PTEN loss of function has a substantial impact in cell development and tumorigenesis (Furnari et al. 2007; Endersby and Baker 2008).

Germline mutations in PTEN are associated with a number of developmental, neurological, and neoplastic diseases, including Cowden's syndrome (85\%), BannayanRiley-Ruvalcaba syndrome (65\%), and Proteus syndrome (20\%) (for review, see Orloff and Eng 2008). These diseases are characterized by hamartomatous growths, abnormal brain development including cerebellar hamartomas, Lhermitte Duclos syndrome (LHD), and cancer predisposition (Chalhoub and Baker 2009). Homozygous PTEN deletion is embryonic lethal. Therefore, mouse models to assess the biology of PTEN have benefitted greatly from Cre-loxP-mediated conditional deletion approaches. Due to the preponderance of brain-associated phenotypes in patients with PTEN germline mutations, significant attention has been given to the development of models in which PTEN is conditionally deleted in the brain. Backman et al. (2001) and Kwon et al. (2001) crossed mice in which PTEN was floxed with transgenic mice expressing Cre-recombinase under a GFAP promoter. This resulted in PTEN deletion primarily in cerebellar granule cells and granule cells of the dentate gyrus of the hippocampus. Both models demonstrated markedly enlarged brains with nearly a doubling in neuronal cell size and abnormal neuronal organization-phenotypes similar to Lhermitte-Duclos disease (Backman et al. 2001; Kwon et al. 2001). Subsequent work from the Baker group (Kwon et al. 2003; Chalhoub et al. 2006) demonstrated that the neuronal hypertrophy was dependent on mTOR, but not S6K1.

Taking a different approach, Groszer et al. (2001) crossed PTEN-floxed mice with transgenic mice expressing Cre-recombinase under the control of a nestin promoter (a gene whose expression is enriched in neural precursor cells). These mice similarly showed massive brain enlargement with increased neuronal cell size and abnormal neuronal organization (Groszer et al. 2001). This group subsequently demonstrated that PTEN deletion in neural stem/progenitor cells enhances constitutive neurogenesis (Gregorian et al. 2009). Taken together, these models demonstrate representative features of PTEN-associated human disease, and demonstrate a critical role for PTEN in regulating neuronal size, proliferation, and organization. Additional mouse models have demonstrated a role for PTEN in regulating neural organization, migration, neuronal and glial differentiation, synaptogenesis, and axonal regeneration (Jaworski et al. 2005; Kwon et al. 2006; Otaegi et al. 2006; Park et al. 2008; for review, see Endersby and Baker 2008). In addition, effects of PTEN deletion have been observed on learning and social behavior (Kwon et al. 2006). Thus, the effects of PTEN deletion on brain architecture and function appear to be highly dependent on the cell type and stage at which PTEN deletion occurs. It is interesting to note that none of these models developed gliomas. Thus, PTEN loss alone is not sufficient for glioma development, a finding consistent with the requirement for multiple pathway coactivations in mouse models of glioblastomagenesis (Endersby and Baker 2008), as well as the evidence for PTEN alterations in association with other mutations in human glioblastoma (The Cancer Genome Atlas Research Network 2008).

\section{PDK1 in balance with PTEN?}

If PTEN can be considered to be the "brakes" on the PI3K pathway, PDK1 potentially could be considered the "gas pedal." PDK1 was first purified from tissue extracts as an enzyme that phosphorylates the T-loop of Akt (Thr308) in the presence of PIP3 (Alessi et al. 1997; Stokoe et al. 1997). PDK1 is known as a master kinase, because in addition to Akt, it also phosphorylates the conserved activation loop residue of many members of other protein kinase families (equivalent to Thr308 of Akt) in different cell types, including S6K, SGK, and PKC kinases (Mora et al. 2004; Bayascas 2008). Similar to PTEN deletion, homozygous deletion of PDK1 is also embryonic lethal, requiring the development of mouse models in which $P D K 1$ is deleted conditionally or in which a hypomorphic allele is expressed. $P D K 1$ hypomorphic mutant mice are only half the size of their wild-type littermates, with markedly diminished somas of many cell types (Lawlor et al. 2002). PDK1 has been postulated recently to play a role in brain development, as it has been shown to be indispensable for neuronal survival during development (Kharebava et al. 2008) and to selectively induce the differentiation of GABAergic neurons through activation of Mash1 (Oishi et al. 2009). Because of its role in promoting PI3K signaling as well as regulating a series of signal transducers involved in promoting cancer growth, proliferation, and survival (Akt, S6K, SGK1, RAK, and PKC), PDK1 has been postulated to be a promising anticancer drug target (Pullen et al. 1998; Peifer and Alessi 2008). In particular, PDK1 may have heightened importance in PTEN-null cancers. An epistatic relationship between Pten and PDK1 has been reported in Drosophila, in which PDK1 deficiency rescued the lethality of dPtendeficient flies (Rintelen et al. 2001). Reducing PDK1 expression in cancer-prone heterozygous $P T E N^{+-}$mice has been shown to greatly reduce the development of a wide range of tumors (Bayascas et al. 2005). However, the contribution of PDK1 in balancing PTEN signaling, particularly in the nervous system, has, up until now, not been elucidated.

In the July 15, 2009, issue of Genes \& Development, Chalhoub et al. (2009) use an elegant mouse genetic approach to determine whether conditional deletion of PDK1 can rescue the effects of PTEN deletion in the brain. They generate strategic conditional knockout models using the Cre-loxP system. They cross a GFAP-cre transgenic line directing Cre-mediated activity throughout the brain in both neurons and glia with nearly complete 
activity in the hippocampus ("hp-cre") (Fraser et al. 2004) with Pten; Pdk1-floxed mice to generate four genotypes used in the study: (1) Pten ${ }^{\text {loxP/loxP }} ;$ Pdk $1^{\text {loxP/t}}$ cre (Pten cKO); (2) Pten ${ }^{\text {loxP/+ }}$; Pdk1 $1^{\text {loxP/loxP }}$; cre (Pdk1 cKO); (3) Pten $^{\text {loxP/loxP }} ;$ Pdk $1^{\text {loxP/loxP }}$; cre (Pten;Pdk1dKO); and (4) No-cre mice (controls). As expected, conditional Pten deletion resulted in macrocephaly, increased neuronal cell size, and abnormal cerebellar neuron migration and layering (Fig. 1A,B). In contrast, Pdk1 cKO mice showed microcephaly (Fig. 1C). Combined Pten:Pdk1 $d K O$ mice showed normal brain size and normal neuronal cell size; however, the migration defect remained (Fig. 1D). Taken together, these results demonstrate PDK1-dependent effects of PTEN loss on brain size and neuronal cell size. They also identify PDK1-independent effects on neuronal migration that were most prominently identified in the cerebellum. A significant reduction of neurons was detected in the cerebella of Pten:Pdk1 dKO mice, consistent with the requirement for PI3K signaling in the granule cell progenitor and survival in the cerebellum (Dudek et al. 1997). Therefore, Chalhoub et al. (2009) used a second GFAP-cre transgenic line with later-onset Cre activity in postnatal cerebellar granule cells ("cb-cre") (Kwon et al. 2001). This strategy allowed them to bypass the early cerebellar requirement for PDK1 for survival and allowed a controlled comparison of cerebella. In this model, Pdk1 deletion rescued the Pten-mediated effects on cerebellar size and neuronal cell size, but it did not rescue the migration defect. This elegant use of models identified both PDK1-dependent and PDK1independent effects of PTEN loss in the brain.

In addition to transducing PI3K-Akt-mediated signals toward protein synthesis, $\mathrm{mTORC} 1$ also acts as a negative regulator of PI3K pathway activation (Sabatini 2006). Thus, deletion of PDK1 could potentially derepress this negative regulator to activate PI3K signaling through Akt, as can be determined by biochemical analysis of Akt Ser473. Unexpectedly, Western blotting analyses of cerebella and hippocampi in the various models revealed up-regulation of Akt (Ser473) phosphorylation in Pdk1deleted glia, but not in Pdk1-deleted neurons, which was confirmed by immunohistochemical analyses of phosphoAkt Ser473 (Fig. 1C). This was shown to be mediated through mTOR/PI3K, as the dual PI3K/mTOR inhibitor BEZ235 abrogated this response. Taken together, these results demonstrate that deletion of $P d k 1$ differentially activates PI3K signaling in glia relative to neurons, raising the concept that the signaling feedback pathways are wired differently in different CNS cells types.

\section{Implications of these findings}

These results have important implications for cancer therapy. PTEN loss is common in many cancers, including glioblastoma. PTEN-null tumors are proving to be particularly difficult to treat, and PTEN loss renders EGFR-activated glioblastomas resistant to EGFR kinase inhibitors (Mellinghoff et al. 2005). Is PDK1 a good target in PTEN-deficient cancer, either alone or in combination with other targeted agents? The results from the study by
Chalhoub et al. (2009) suggest that targeting PDK1 may not fully inhibit the spectrum of pathology induced by PTEN loss, as PDK1 did not prevent abnormal cellular migration induced by PTEN deficiency. It is not clear whether these PTEN-mediated effects on migration are PI3K-dependent or PDK1-independent, or whether they are mediated by PI3K-independent signaling. PTEN contains both a lipid phosphatase that is required for antagonizing PI3K signaling and a protein phosphatase domain that has been implicated in regulating other cancerpromoting signaling pathways, such as Src family kinases (Dey et al. 2008). Future studies will be needed to determine whether these effects are mediated through, or are independent of, $\mathrm{PI} 3 \mathrm{~K}$ signaling, and to assess their downstream effectors. However, before PDK1 inhibitors are discounted in PTEN-null cancers, it needs to be recognized that in addition to Akt signaling, PDK1 also regulates a number of other enzymes such as SGK1, PKC $\alpha$, and S6K, all of which are up-regulated in many cancers. Thus, PDK1 inhibitors could have significant anti-growth effects on tumors independent of their effect on PI3K signaling.

The most intriguing and unexpected finding in the study by Chalhoub et al. (2009) is the demonstration that feedback signaling to PI3K occurs in glia but not neurons. mTORC1 links growth factor signals with cellular proliferation and protein translation, but it also can serve as a negative regulator of PI3K pathway activation. mTORC1 impairs PI3K activation in growth factor-stimulated cells by down-regulating IRS1, IRS2, and PDGFR (Sarbassov et al. 2005; Sabatini 2006; Zhang et al. 2007), presumably to keep PI3K pathway signaling in check. In fact, derepression of mTORC1-mediated feedback by treatment with rapamycin has been shown to be associated with more rapid clinical progression in glioblastoma patients (Cloughesy et al. 2008). Thus, understanding how feedback is regulated is critical for cancer therapy. These studies suggest that feedback activation is cell context-dependent, and demonstrate that feedback signaling cannot be studied adequately outside relevant cell contexts.

These studies also raise the need to identify interacting proteins that differentially regulate feedback activation of PI3K signaling in glia versus neurons. Chalhoub et al. (2009) point out that post-mitotic neurons do not require the exquisite level of pathway regulation required by astrocytes and oligodendrocytes, which maintain the ability to proliferate. What are the molecular mechanisms underlying this phenomenon? The fact that the dual PI3K/mTOR inhibitor BEZ235 inhibits feedback activation in Pkd1-deleted glia (Supplemental Fig. S6B of Chalhoub et al. 2009), indicates that the feedback loop is mTOR-mediated and/or PI3K-mediated. However, is the feedback activation mTORC2-dependent, as suggested by Akt473 phosphorylation? If so, is it amenable to inhibition by mTOR kinase inhibitors? The mTORinteracting protein DEPTOR has been identified recently as a key determinant of mTORC-1-mediated inhibition of PI3K signaling. DEPTOR is both a negative regulator of and negatively regulated by mTORC1 and mTORC2, and 


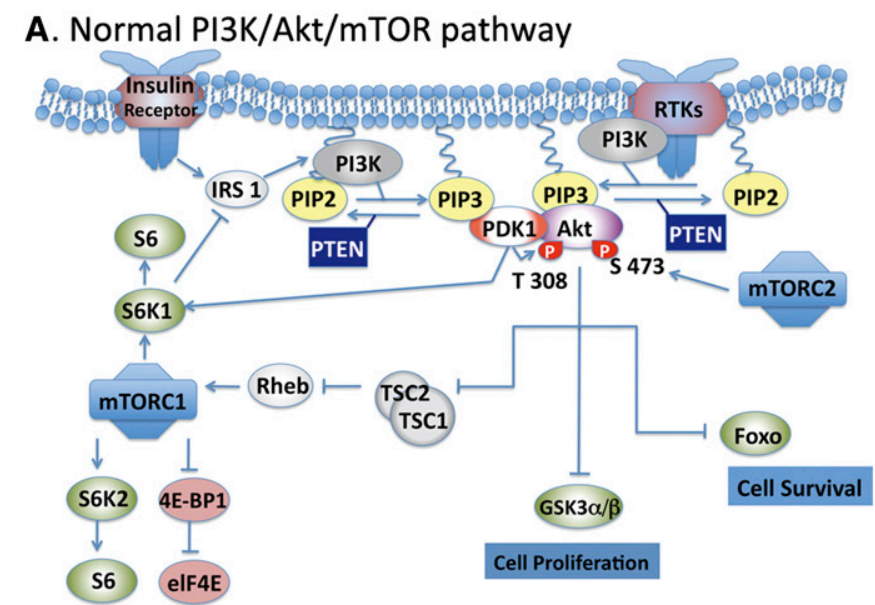

\section{Protein Translation}

\section{Pdk1 conditional KO mice}

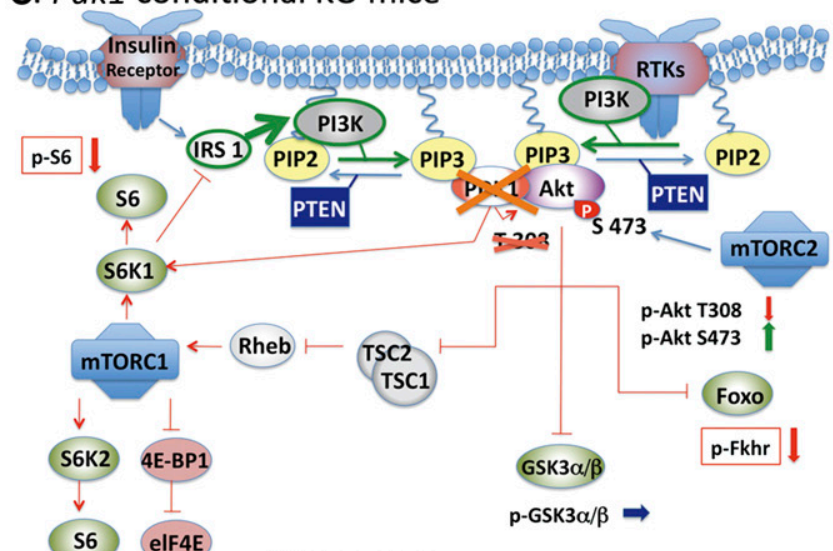

Microcephaly

Feedback PI3K activation in Glia

but not in Neurons
B. Pten conditional KO mice

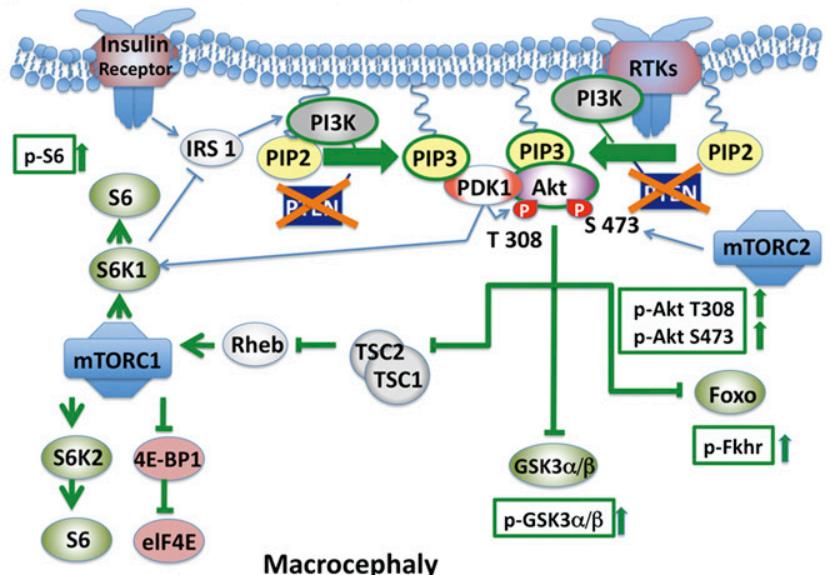

Increased neuronal cell size

Migration defect

D. Pten/Pdk1 double KO mice

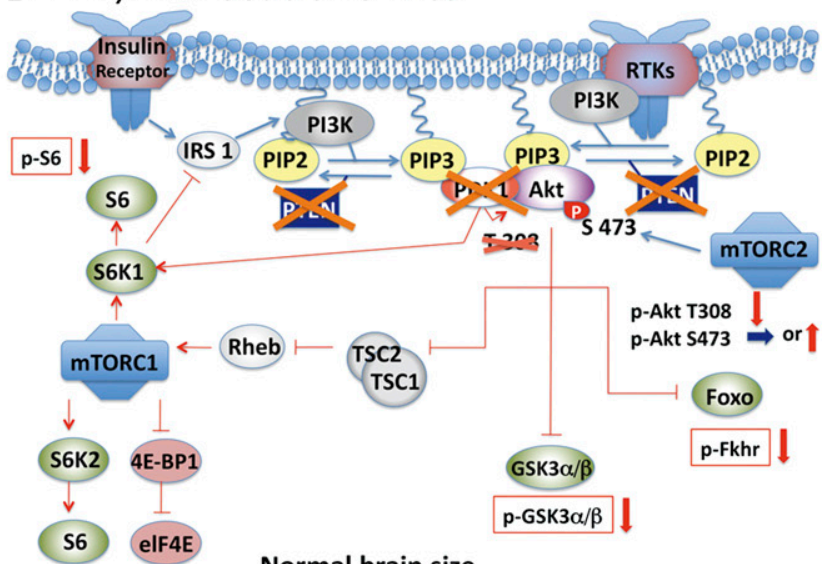

Normal brain size

Normal neuronal cell size

Migration defect persists

Normal

Upregulation

Downregulation

Figure 1. Summary of consequences on signal transduction and brain architecture of conditional Pten or Pdk1 deletion, alone or in combination. (A) Under normal levels of PI3K/Akt/mTOR pathway activation, PTEN and PDK1 activities are in balance. (B) Conditional deletion of Pten with nearly complete activity in the hippocampus "hp-cre" results in hyperactivation of Akt/mTOR signaling with macrocephaly, increased neuronal cell size, and cerebellar neuronal migration defect. (C) Conditional deletion of PDK1 suppresses Akt/mTOR signaling and causes microcephaly. Up-regulation of PI3K via derepression of mTORC1 is detected in glia but not in neurons. (D) Pdk1 deletion rescues Pten deletion-mediated macrocephaly and prevents Pten deletion-mediated increase in neuronal cell size. However, $P d k 1$ deletion cannot rescue the effect on abnormal neuronal migration.

its overexpression can activate PI3K by relieving mTORC1mediated inhibitory feedback (Peterson et al. 2009). It remains to be determined whether DEPTOR plays a role in the differential PI3K pathway activation observed upon PDK1 loss in neurons versus glia. Furthermore, DEPTOR has also been shown to be down-regulated in many cancers, including malignant gliomas in which its expression is greatly reduced relative to normal brains (Peterson et al. 2009). Does DEPTOR loss in these cancers imply a loss of control of the mTOR regulation above and beyond that promoted by unrestrained PI3K activation and, if so, what are the cellular consequences of unrestrained mTORC2 signaling?

Lastly, the study by Chalhoub et al. (2009) suggests that biologically important signaling systems are not simple linear pathways, but rather complex dynamic networks in which feedback and cross-talk are critical for determining cellular outcome. These studies raise the question 
of whether magnitude of flux through the PI3k/Akt/ mTOR signaling pathway is important for determining its wiring. In an elegant study published in the March 15, 2007, issue of Genes \& Development, Hietakangas and Cohen (2007) demonstrated through genetic disruption of the TORC2 complex proteins rictor and $\sin 1$ and/or genetic disruption of the Akt hydrophobic motif containing Ser473 in Drosophila that failure of TORC2-mediated phosphorylation of Akt results in only minor growth impairment at normal levels of PI3K pathway activation. However, in PTEN-deficient flies, loss of TORC2 activity significantly inhibited hyperplasia (Hietakangas and Cohen 2007). Does mTORC2 signaling have enhanced importance in the context of increased signal flux through the PI3K pathway? What about in the context of PI3K pathway hyperactivation, as occurs in many cancers, including malignant gliomas (The Cancer Genome Atlas Research Network 2008)? EGFR amplification in combination with PTEN loss is extremely common in glioblastomas (The Cancer Genome Atlas Research Network 2008), as are other PI3K coactivating alterations (Stommel et al. 2007). Constitutive coactivation of EGFR-Ras-Akt pathways in Drosophila glia and glial precursors gave rise to invasive gliomas in which TORC2 complex members (Sin 1 and rictor) were required for glial proliferation, but not for normal development (Read et al. 2009). These studies suggested that in the context of PI3K pathway hyperactivation, mTORC2 signaling may take on heightened importance. In summary, the work of Chalhoub et al. (2009) has provided a novel and important demonstration of cell context-specific differences in feedback regulation that hint at crucial differences in the wiring of the PI3K/Akt/mTOR signaling pathway between neurons and glia and suggest even further alterations in glial tumors. Future work, particularly studies that tease out this circuitry in well-defined cell contexts, is needed.

\section{Acknowledgments}

We apologize to authors whose work we were not able to cite due to format restrictions. We thank Dr. Webster Cavenee and Dr. George Thomas for helpful discussion and comments on this manuscript. P.S.M. and T.F.C. are supported by grants from National Institute for Neurological Diseases and Stroke (NS05051), the National Cancer Institute (CA119347 and CA108633), the Brain Tumor Funders' Collaborative, The Ben and Catherine Ivy Foundation, Accelerate Brain Cancer Cure, the Harry Allgauer Foundtion through The Doris R. Ullman Fund for Brain Tumor Research Technologies, the Henry E. Singleton Brain Tumor Program, and generous donations from the Ziering Family Foundation in memory of Sigi Ziering and Timothy and Mary Hanneman. A.I. was supported in part by a grant from the Japan Society for Promotion of Science.

\section{References}

Alessi DR, James SR, Downes CP, Holmes AB, Gaffney PR, Reese CB, Cohen P. 1997. Characterization of a 3-phosphoinositidedependent protein kinase which phosphorylates and activates protein kinase B $\alpha$. Curr Biol 7: 261-269.

Backman SA, Stambolic V, Suzuki A, Haight J, Elia A, Pretorius J, Tsao MS, Shannon P, Bolon B, Ivy GO, et al. 2001. Deletion of Pten in mouse brain causes seizures, ataxia and defects in soma size resembling Lhermitte-Duclos disease. Nat Genet 29: 396-403.

Bayascas JR. 2008. Dissecting the role of the 3-phosphoinositidedependent protein kinase-1 (PDK1) signalling pathways. Cell Cycle 7: 2978-2982.

Bayascas JR, Leslie NR, Parsons R, Fleming S, Alessi DR. 2005. Hypomorphic mutation of PDK1 suppresses tumorigenesis in PTEN ${ }^{+/-}$mice. Curr Biol 15: 1839-1846.

Calleja V, Alcor D, Laguerre M, Park J, Vojnovic B, Hemmings BA, Downward J, Parker PJ, Larijani B. 2007. Intramolecular and intermolecular interactions of protein kinase $\mathrm{B}$ define its activation in vivo. PLOS Biol 5: e95. doi: 10.1371/journal. pbio.0050095.

Calleja V, Laguerre M, Parker PJ, Larijani B. 2009. Role of a novel $\mathrm{PH}$-kinase domain interface in $\mathrm{PKB} /$ Akt regulation: Structural mechanism for allosteric inhibition. PLoS Biol 7: e17. doi: 10.1371/journal.pbio.1000017.

The Cancer Genome Atlas Research Network. 2008. Comprehensive genomic characterization defines human glioblastoma genes and core pathways. Nature 455: 1061-1068.

Chalhoub N, Baker SJ. 2009. PTEN and the PI3-kinase pathway in cancer. Annu Rev Pathol 4: 127-150.

Chalhoub N, Kozma SC, Baker SJ. 2006. S6k1 is not required for Pten-deficient neuronal hypertrophy. Brain Res 1100: 32-41.

Chalhoub N, Zhu G, Zhu X, Baker SJ. 2009. Cell type specificity of PI3K signaling in Pdk1- and Pten-deficient brain. Genes \& Dev 23: 1619-1624.

Cloughesy TF, Yoshimoto K, Nghiemphu P, Brown K, Dang J, Zhu S, Hsueh T, Chen Y, Wang W, Youngkin D, et al. 2008. Antitumor activity of rapamycin in a Phase I trial for patients with recurrent PTEN-deficient glioblastoma. PLoS Med 5: e8. doi: 10.1371/journal.pmed.0050008.

Dey N, Crosswell HE, De P, Parsons R, Peng Q, Su JD, Durden DL. 2008. The protein phosphatase activity of PTEN regulates SRC family kinases and controls glioma migration. Cancer Res 68: 1862-1871.

Dudek H, Datta SR, Franke TF, Birnbaum MJ, Yao R, Cooper GM, Segal RA, Kaplan DR, Greenberg ME. 1997. Regulation of neuronal survival by the serine-threonine protein kinase Akt. Science 275: 661-665.

Endersby R, Baker SJ. 2008. PTEN signaling in brain: Neuropathology and tumorigenesis. Oncogene 27: 5416-5430.

Engelman JA, Luo J, Cantley LC. 2006. The evolution of phosphatidylinositol 3-kinases as regulators of growth and metabolism. Nat Rev Genet 7: 606-619.

Fan QW, Cheng C, Knight ZA, Haas-Kogan D, Stokoe D, James CD, McCormick F, Shokat KM, Weiss WA. 2009. EGFR signals to mTOR through PKC and independently of Akt in glioma. Sci Signal 2: ra4. doi: 10.1126/scisignal.2000014.

Fraser MM, Zhu X, Kwon CH, Uhlmann EJ, Gutmann DH, Baker SJ. 2004. Pten loss causes hypertrophy and increased proliferation of astrocytes in vivo. Cancer Res 64: 77737779.

Furnari FB, Fenton T, Bachoo RM, Mukasa A, Stommel JM, Stegh A, Hahn WC, Ligon KL, Louis DN, Brennan C, et al. 2007. Malignant astrocytic glioma: Genetics, biology, and paths to treatment. Genes \& Dev 21: 2683-2710.

Gregorian C, Nakashima J, Le Belle J, Ohab J, Kim R, Liu A, Smith KB, Groszer M, Garcia AD, Sofroniew MV, et al. 2009. Pten deletion in adult neural stem/progenitor cells enhances constitutive neurogenesis. J Neurosci 29: 1874-1886.

Groszer M, Erickson R, Scripture-Adams DD, Lesche R, Trumpp A, Zack JA, Kornblum HI, Liu X, Wu H. 2001. Negative regulation of neural stem/progenitor cell proliferation by the Pten tumor suppressor gene in vivo. Science 294: 2186-2189. 
Guertin DA, Sabatini DM. 2009. The pharmacology of mTOR inhibition. Sci Signal 2: pe24. doi: 10.1126/scisignal.267pe24.

Hietakangas V, Cohen SM. 2007. Re-evaluating AKT regulation: Role of TOR complex 2 in tissue growth. Genes \& Dev 21: 632-637.

Jaworski J, Spangler S, Seeburg DP, Hoogenraad CC, Sheng M. 2005. Control of dendritic arborization by the phosphoinositide3'-kinase-Akt-mammalian target of rapamycin pathway. J Neurosci 25: 11300-11312.

Kharebava G, Makonchuk D, Kalita KB, Zheng JJ, Hetman M. 2008. Requirement of 3-phosphoinositide-dependent protein kinase-1 for BDNF-mediated neuronal survival. I Neurosci 28: 11409-11420.

Kwon CH, Zhu X, Zhang J, Knoop LL, Tharp R, Smeyne RJ, Eberhart CG, Burger PC, Baker SJ. 2001. Pten regulates neuronal soma size: A mouse model of Lhermitte-Duclos disease. Nat Genet 29: 404-411.

Kwon $\mathrm{CH}$, Zhu X, Zhang J, Baker SJ. 2003. mTor is required for hypertrophy of Pten-deficient neuronal soma in vivo. Proc Natl Acad Sci 100: 12923-12928.

Kwon CH, Luikart BW, Powell CM, Zhou J, Matheny SA, Zhang W, Li Y, Baker SJ, Parada LF. 2006. Pten regulates neuronal arborization and social interaction in mice. Neuron 50: 377388.

Lawlor MA, Mora A, Ashby PR, Williams MR, Murray-Tait V, Malone L, Prescott AR, Lucocq JM, Alessi DR. 2002. Essential role of PDK1 in regulating cell size and development in mice. EMBO J 21: 3728-3738.

Mellinghoff IK, Wang MY, Vivanco I, Haas-Kogan DA, Zhu S, Dia EQ, Lu KV, Yoshimoto $\mathrm{K}$, Huang $\mathrm{JH}$, Chute DJ, et al. 2005. Molecular determinants of the response of glioblastomas to EGFR kinase inhibitors. N Engl I Med 353: 2012 2024.

Mora A, Komander D, van Aalten DM, Alessi DR. 2004. PDK1, the master regulator of AGC kinase signal transduction. Semin Cell Dev Biol 15: 161-170.

Oishi K, Watatani K, Itoh Y, Okano H, Guillemot F, Nakajima K, Gotoh Y. 2009. Selective induction of neocortical GABAergic neurons by the PDK1-Akt pathway through activation of Mash1. Proc Natl Acad Sci doi: 10.1073/pnas.0808400106.

Orloff MS, Eng C. 2008. Genetic and phenotypic heterogeneity in the PTEN hamartoma tumour syndrome. Oncogene 27: 5387-5397.

Otaegi G, Yusta-Boyo MJ, Vergano-Vera E, Mendez-Gomez HR, Carrera AC, Abad JL, Gonzalez M, de la Rosa EJ, VicarioAbejon C, de Pablo F. 2006. Modulation of the PI 3-kinaseAkt signalling pathway by IGF-I and PTEN regulates the differentiation of neural stem/precursor cells. J Cell Sci 119: $2739-2748$.

Park KK, Liu K, Hu Y, Smith PD, Wang C, Cai B, Xu B, Connolly L, Kramvis I, Sahin M, et al. 2008. Promoting axon regeneration in the adult CNS by modulation of the PTEN/ mTOR pathway. Science 322: 963-966.

Peifer C, Alessi DR. 2008. Small-molecule inhibitors of PDK1. ChemMedChem 3: 1810-1838.

Peterson TR, Laplante M, Thoreen CC, Sancak Y, Kang SA, Kuehl WM, Gray NS, Sabatini DM. 2009. DEPTOR is an mTOR inhibitor frequently overexpressed in multiple myeloma cells and required for their survival. Cell 137: 873-886.

Pullen N, Dennis PB, Andjelkovic M, Dufner A, Kozma SC, Hemmings BA, Thomas G. 1998. Phosphorylation and activation of p70s6k by PDK1. Science 279: 707-710.

Read RD, Cavenee WK, Furnari FB, Thomas JB. 2009. A Drosophila model for EGFR-Ras and PI3K-dependent human glioma. PLoS Genet 5: e1000374. doi: 10.1371/journal.pgen. 1000374.
Rintelen F, Stocker H, Thomas G, Hafen E. 2001. PDK1 regulates growth through Akt and S6K in Drosophila. Proc Natl Acad Sci 98: 15020-15025.

Sabatini DM. 2006. mTOR and cancer: Insights into a complex relationship. Nat Rev Cancer 6: 729-734.

Sarbassov DD, Guertin DA, Ali SM, Sabatini DM. 2005. Phosphorylation and regulation of Akt/PKB by the rictor-mTOR complex. Science 307: 1098-1101.

Stokoe D, Stephens LR, Copeland T, Gaffney PR, Reese CB, Painter GF, Holmes AB, McCormick F, Hawkins PT. 1997. Dual role of phosphatidylinositol-3,4,5-trisphosphate in the activation of protein kinase B. Science 277: 567-570.

Stommel JM, Kimmelman AC, Ying H, Nabioullin R, Ponugoti $\mathrm{AH}$, Wiedemeyer R, Stegh AH, Bradner JE, Ligon KL, Brennan C, et al. 2007. Coactivation of receptor tyrosine kinases affects the response of tumor cells to targeted therapies. Science 318: 287-290.

Vivanco I, Sawyers CL. 2002. The phosphatidylinositol 3-Kinase AKT pathway in human cancer. Nat Rev Cancer 2: 489-501.

Zhang H, Bajraszewski N, Wu E, Wang H, Moseman AP, Dabora SL, Griffin JD, Kwiatkowski DJ. 2007. PDGFRs are critical for PI3K/Akt activation and negatively regulated by mTOR. J Clin Invest 117: 730-738. 


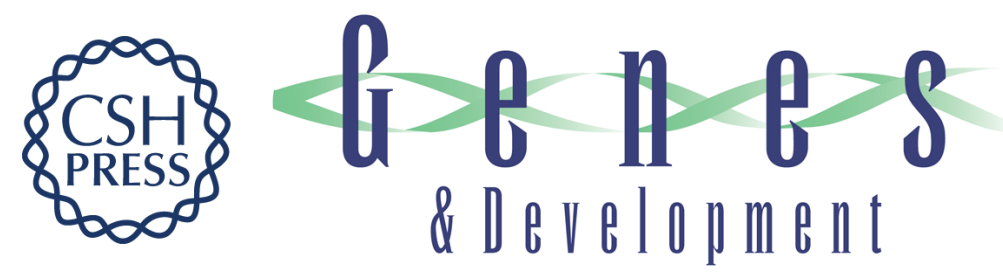

\section{Striking the balance between PTEN and PDK1: it all depends on the cell context}

Akio Iwanami, Timothy F. Cloughesy and Paul S. Mischel

Genes Dev. 2009, 23:

Access the most recent version at doi:10.1101/gad.1832909
Related Content Cell type specificity of PI3K signaling in Pdk1- and Pten-deficient brains Nader Chalhoub, Guo Zhu, Xiaoyan Zhu, et al.
Genes Dev. July , 2009 23: 1619-1624
References This article cites 45 articles, 22 of which can be accessed free at: http://genesdev.cshlp.org/content/23/15/1699.full.html\#ref-list-1
Articles cited in:
http://genesdev.cshlp.org/content/23/15/1699.full.html\#related-urls
License
Email Alerting
Receive free email alerts when new articles cite this article - sign up in the box at the top right corner of the article or click here.

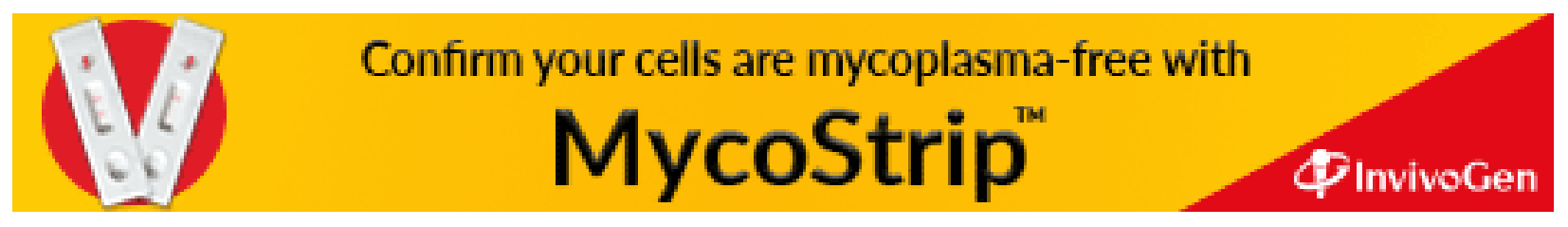

